\title{
Evaluation of Results of the Furlow's Modified Technique in the Management of Cleft Palate in the Teaching Hospital of Conakry
}

\author{
Oumar Raphiou Diallo1, Alpha Oumar Diallo², Alhassane Conde1, \\ Thierno Abdourahmane Balde1, Karamoko Alpha Diallo1, Gary Parker ${ }^{3}$ \\ ${ }^{1}$ Department of Odontostomatology and Maxillo-Facial Surgery, Donka Hospital, Conakry, Guinea \\ ${ }^{2}$ Department of ENT, Ignace Deen Hospital, Conakry, Guinea \\ ${ }^{3} \mathrm{M} / \mathrm{V}$ Africa Mercy, Mercy Ships, Port of Conakry, Conakry, Guinea \\ Email: rafioumajid@yahoo.fr
}

How to cite this paper: Diallo, O.R., Diallo, A.O., Conde, A., Balde, T.A., Diallo, K.A. and Parker, G. (2021) Evaluation of Results of the Furlow's Modified Technique in the Management of Cleft Palate in the Teaching Hospital of Conakry. Open Journal of Stomatology, 11, 25-36.

https://doi.org/10.4236/ojst.2021.111003

Received: November 1, 2020

Accepted: January 23, 2021

Published: January 26, 2021

Copyright $\odot 2021$ by author(s) and Scientific Research Publishing Inc. This work is licensed under the Creative Commons Attribution International License (CC BY 4.0).

http://creativecommons.org/licenses/by/4.0/

(c) (i) Open Access

\begin{abstract}
Introduction: Cleft palate $(\mathrm{CP})$ is a congenital dysmorphosis that results from a failure of the palatal processes of the maxillary buds and nasal septum to merge. The objectives of this study were to determine the frequency of complications of the modified Furlow technique and to evaluate its anatomical and functional outcomes. Materials and Method: This was a retrospective study that took place over a period of 4 years (from January $1^{\text {st }}, 2015$ to December $31^{\text {th }}, 2018$ ) in the Department of Odontostomatology and Maxillofacial Surgery at the National Hospital of Donka (Conakry, Guinea). Data retrieval consisted of records from patients operated on for cleft palate according to Furlow's modified technique only. The operative technique consisted of marginal incisions of the cleft according to the technique of the double Z-plasty of Furlow. Subsequently, the defect created between the 2 flaps and the anterior edge of the cleft was filled by two fat masses of Bichat sutured to each other with Vicryl 3-0. Four years after surgery, the patients were recalled for an evaluation of the anatomical and functional results. Results: 13 patients underwent surgical loading according to the modified Furlow technique. The average age of the patients was 6.9 years with an age range of 7 months and 17 years. Females were the most affected, with $61.54 \%$ of cases and a sex ratio of 0.62 . The primary repair rate was $84.61 \%$ of cases. Immediate operative follow-up was simple with epithelialization of the flaps in all patients. Four (4) years after the surgeries, 12 patients were reevaluated $(92.30 \%)$, among them one case $(8.33 \%)$ of fistula complication was noted. The mobility of the veil and the phonation were good in $85.71 \%$ and $60 \%$ respectively. Articular disorders with nasonation were found in 2 patients (16.67\%). Swallowing was normal in $85.72 \%$ of cases. Conclusion: The modified Furlow
\end{abstract}


technique is an important contribution to cleft palate surgery significantly reducing the occurrence of postoperative complications. However, the delay of the surgical operation remains a real obstacle for obtaining a normal phonation.

\section{Keywords}

Cleft Palate, Furlow, Evaluation

\section{Introduction}

Cleft palates (CP) are common congenital dysmorphosis. They result from failure of the palatal processes of the maxillary buds and the nasal septum to merge [1]. The family of newborn babies with this abnormality first encountered social issues, followed by dysfunction affecting their diet, and the normal development of language [2]. The therapeutic management of these children from their birth to the end of their adolescence is multidisciplinary and includes many specialties.

The challenge in $\mathrm{CP}$ treatment is not only closing the palate but also correcting and obtaining almost normal swallowing and phonation, as well as preventing postoperative fistulas and preserving facial growth [3].

Several surgical techniques have been developed for CP repair, but there is still controversy over the best technique for their management. In $15 \%$ to $45 \%$ of cases, there is a velo-pharyngeal insufficiency after the primary repair of the $\mathrm{CP}$, requiring a secondary repair [3]. Furlow'spalatoplasty or double Z-plasty was first used in 1978 (USA). Several series have shown this technique allows an elongation of the soft palate, a reorientation of the muscles leading to better phonatory results, and a decrease in the rate of postoperative fistulas [4] [5] [6]. However in the case of wide clefts, the tension-free closure of the sutures is difficult to achieve at the hard-soft palate junction thus increasing the fistula rate [7]. To overcome this difficulty, the authors made several modifications to the initial technique described by Leonard Furlow such as using Bichat fat or Bichat flap by Levi et al. [8], a vestibular flap, VY plasty, and combination of CP with Langhenbeck technique [3] [7]. For ten years, the Maxillofacial Department at Donka Hospital uses the modified Furlow technique combined to the Bichat fat pad. This fat ball is widely used in maxillofacial surgery for the closure of oral-sinus communication and the effectiveness efficiency in closing $\mathrm{CP}$ is supported by authors like Levi B et al. [8] and Singh J et al. [9].

Since no study exists in Guinea on the evaluation of the results of the modified Furlow technique, we conducted the study to determine the frequency of complications and evaluate the anatomical and functional results of this technique.

\section{Materials and Method}

This was a 4-year retrospective study, from January $1^{\text {st }}, 2015$ to December $31^{\text {st }}$, 
2018 in the Department of Odontostomatology Maxillofacial Surgery at the National Hospital, Donka.

The sampling was exhaustive and covered all the files of patients treated according to the modified Furlow technique. We included in this study, record of patients operated for $\mathrm{CP}$ according to Furlow's modified technique with or without a cheiloplasty. All the records of patients operated for CP using other repair techniques were not included.

\subsection{Operating Protocol}

Under general anesthesia, plots of the double Z-plasty incisions were made after infiltration with xylocaine $1 \%$, into the palatal mucosa (Image 1 and Image 2). Incisions were made on the free edge of the cleft to the junction between the oral mucosa and nasal, allowing the release of the first two flaps. These are subsequently sectioned to obtain four flaps (two of each hemi soft palate).

When the posterior edge of the anterior oral flap is approximated to the anterior edge of the posterior oral flap to close the palatal defect, the new soft palate is pulled forward undoing much of the gained length (Image 3). To avoid this, an incision is made at the level of the maxillary tuberosity followed by dissection and exposure of the buccal fat (Image 4). Then, the buccal fat flaps are gently drawn together to obliterate the palatal defect without shortening the new palate (Image 5(a) and Image 5(b)).

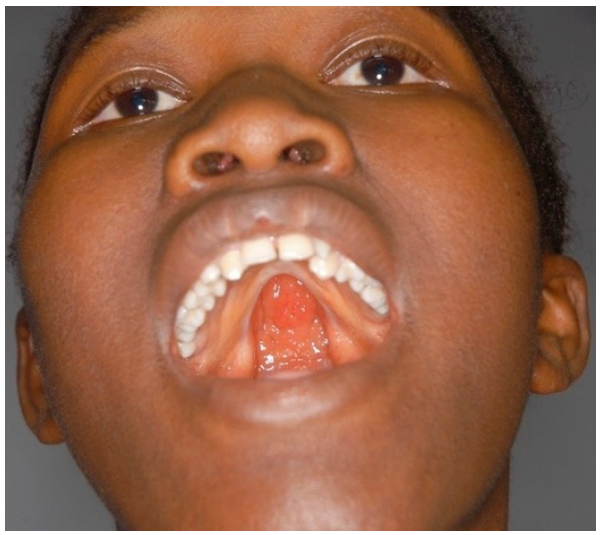

Image 1. Patient before operation.

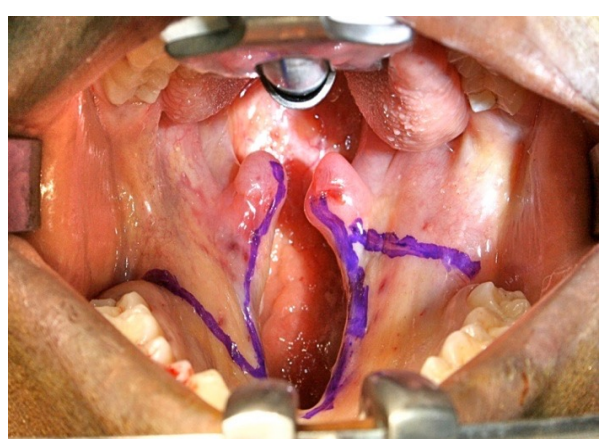

Image 2. Schemas of future incision lines. 


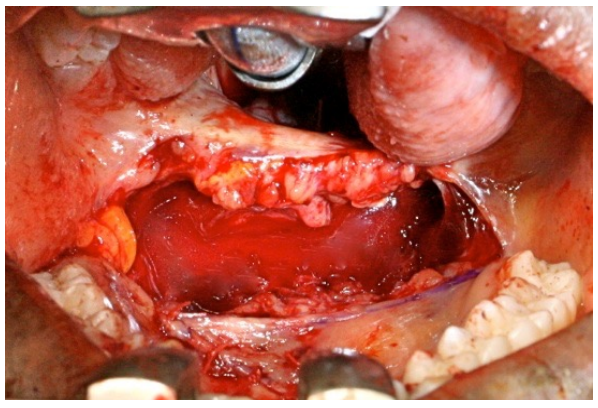

Image 3. Elevation of the two flaps (mucous and musculo-mucous) and suture (after suture, the new soft palate is pushed forward, undoing much of the gained length).

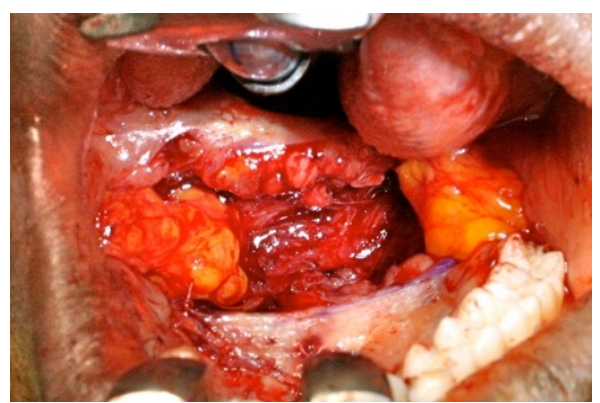

Image 4. Dissection and exposure of the buccal fat.

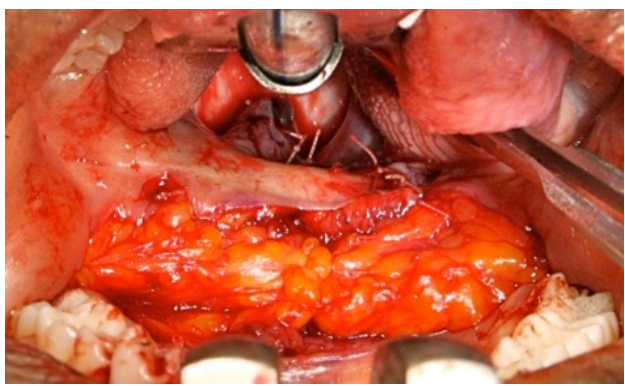

(a)

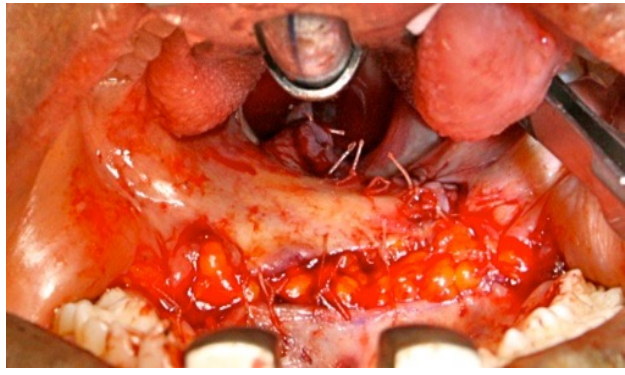

(b)

Image 5. (a) The buccal fat flaps are drawn together to obliterate the palatal defect. (b) The buccal fat flaps are suture together with the mucosal flaps to close the palatal defect without shortening the new palate. 


\subsection{Evaluation of the Anatomical Results of the Technique}

The evaluation of the immediate operative follow-up comprised the evaluation of healing or scarring of the flaps, the epithelialization of the flaps of Bichat, and investigation of the complications: infection, dehiscence, hemorrhage, and fistula.

Four (4) years after surgery, patients were recalled to evaluate the results of the technique. This evaluation made it possible to assess the following parameters: late postoperative complications, fistula, length of the palate, mobility of the veil, swallowing, and phonation.

For this purpose, an intra-oral clinical examination was performed to assess the length of the veil (this is the measure of the postoperative lengthening of the soft palate). For the measurement of this length, a graduated flexible rule was used.

Measurement technique: with the patient in supine position and the mouth open, the point connecting the center of two central incisors and the lining of the palate was determined as the starting point and the tip of the uvula as the end point.

\subsection{Evaluation of the Type of Phonation}

For the evaluation of phonation, the patients were asked to pronounce alphabetic letters namely: the constrictive consonants; S/J/Z/, plosives: /P and B/, nasals: $/ \mathrm{M} /$.

Phonation has been classified into 3 types according to Borel-Maisonny classification [10]:

Phonation type I-no nasality.

Phonation type II—intermittent nasality; II B-good intelligibility; II M-poor intelligibility.

Phonation type III-the nasality is permanent with mechanisms of compensation and bad intelligibility. This type is divided in 2 sub types namely: III Bacceptable and III M-difficult communication. Phonation was regarded as good for patients with type I and II B; "without or with a slight nasonation giving a good intelligibility of the voice".

It was regarded as bad for patients with type II M and III phonation; "nasonation making the voice unintelligible".

\subsection{Evaluation of Swallowing}

Swallowing was evaluated by looking for regurgitation or false routes in patients.

Ethical consideration: since the patients were underage, written and verbal ethical consent was obtained from parents and legal guardians. Confidentiality of data was also ensured.

Ethical consideration: Since the patients were underage, written and verbal ethical consent was obtained from parents and legal guardians. Confidentiality of data was also ensured. 


\section{Results}

A total of 13 patients were reviewed consisted of 5 (46\%) males and 8 (54\%) females, providing a gender ratio of $0.62: 1$. The age distribution was as follows: 7 patients from 0 - 5 years (53.85\%), 3 patients from 6 - 10 years (23.07\%), 2 patients from 11 - 15 years (15.39\%), and 1 patient between 16 - 20 years (7.69\%). The age range was 7 months to 17 years, with a mean age of 6.9 years (Figure 1).

Table 1 shows the distribution of patients according to type of cleft palate. Left side unilateral complete cleft palate was most common at $6(46.17 \%)$, bilateral complete cleft palate and isolated cleft palate were $3(23.07 \%)$ each, while right side unilateral incomplete cleft palate was the least common at 1 (7.69\%).

The distribution of patients by age at intervention is presented in Figure 2. The age range 6 - 10 years has the highest number of intervention 4 (30.79\%), while 7 months-2 years, 3 - 5 years, and 11 - 17 year shad 3 (23.07\%)each.

The methods of surgical repair administered on the patients is presented in Table 2.

According to the type of intervention on the palate, $84.61 \%(\mathrm{n}=11)$ had primary reparation and 2 patients (15.39\%) - a secondary reparation.

Average duration of hospital stay: 5.3 days.

\subsection{Immediate Operative Follow-Up and Scarring of Bichat Flaps}

The epithelialization of the flaps with complete closure of the palatal clefts was obtained in all cases (Image 6(a) and Image 6(b)). No immediate postoperative complications were noted. The outcome of 12 long-term follow-up patients were reevaluated, 11 (91.67\%) had no morphological complication, and 1 (8.33\%) fistula was noted.

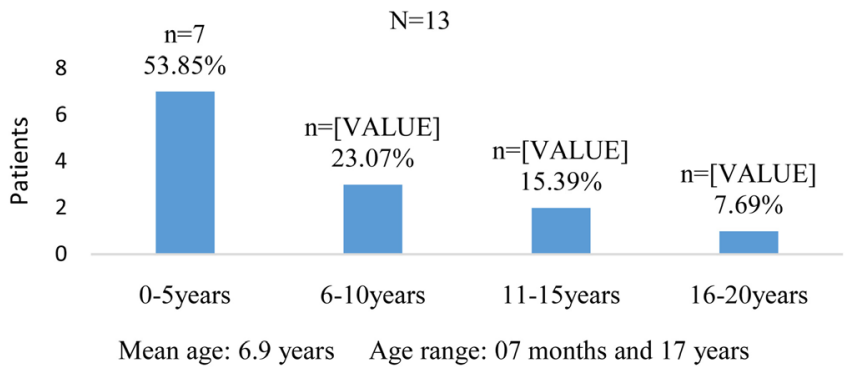

Figure 1. Distribution of patients by age.

Table 1. Distribution of patients by type of cleft palate.

\begin{tabular}{ccc}
\hline Cleftpalate & Frequency & Percentage \\
\hline Unilateral incomplete cleft palate (right side) & 1 & 7.69 \\
Bilateralcompletecleftpalate & 3 & 23.07 \\
Unilateral complete cleft palate (left side) & 6 & 46.17 \\
Soft palatecleft & 3 & 23.07 \\
Total & 13 & 100 \\
\hline
\end{tabular}




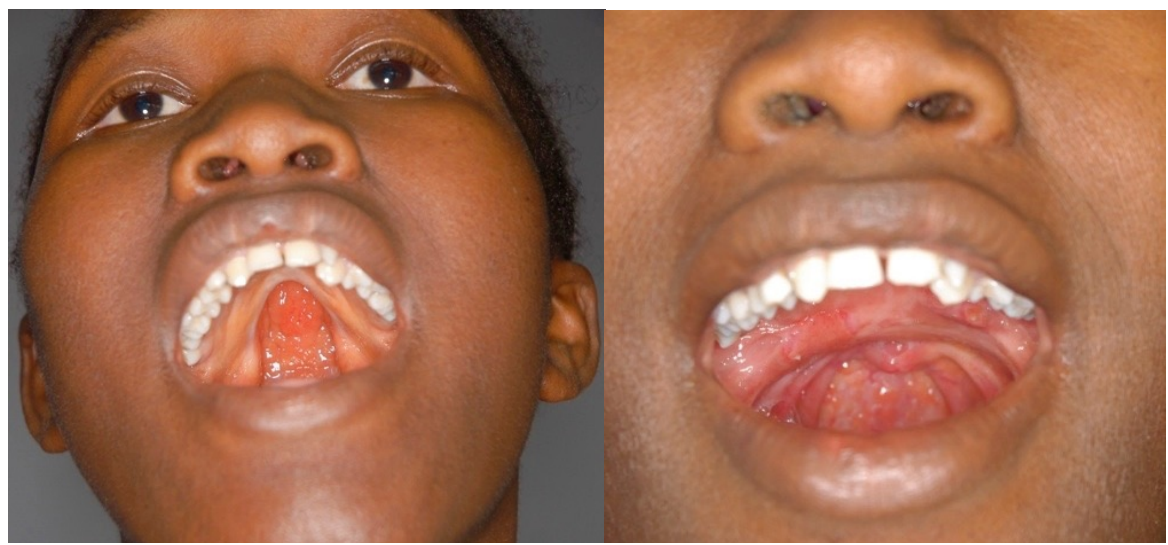

(a)

(b)

Image 6. Patient before and 6 month after operation with complete epithelization of the buccal fat.

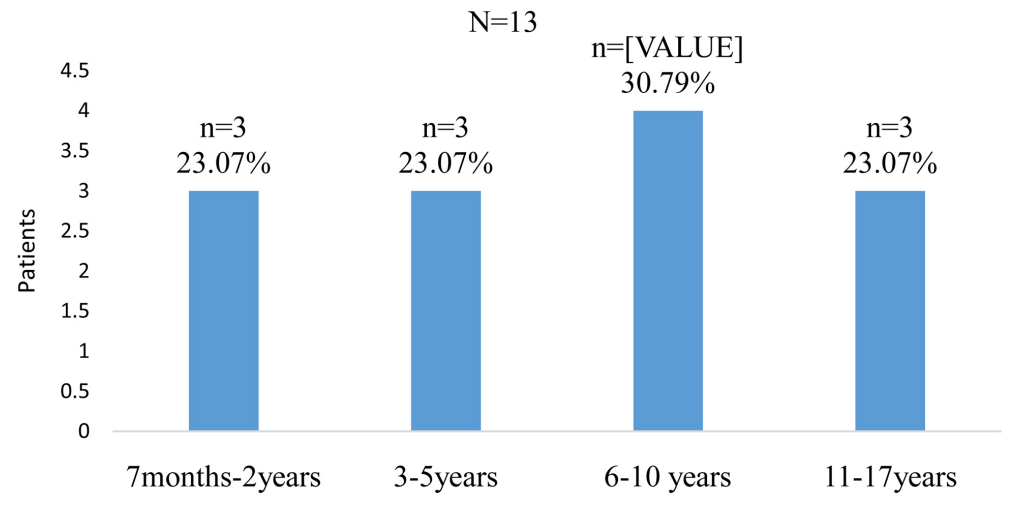

Figure 2. Distribution of patients by age at intervention.

Table 2. Distribution of patients according to the surgical treatment.

\begin{tabular}{lcc}
\hline \multicolumn{1}{c}{ Surgicaltreatment } & Frequency & Percentage \\
\hline Modified Furlow and Bilateral Cheiloplasty: & & \\
- Straight-Line & 1 & 7.69 \\
- Furlowmodifiedalone & 3 & 23.08 \\
Modified Furlow and Millard Cheiloplasty & 5 & 38.47 \\
Modified Furlow and Lip/Nose Review & 4 & 30.76 \\
Total & 13 & 100 \\
\hline
\end{tabular}

\subsection{Length of the Palate, Mobility of the Veil and Position of the Uvula}

The total length of the palate was measured for 8 patients (66.67\%) with an average of $9.44 \mathrm{~cm}$. The patient's respective measurements were $6 \mathrm{~cm}, 6.60 \mathrm{~cm}, 7$ $\mathrm{cm}, 9 \mathrm{~cm}, 10 \mathrm{~cm}, 11.40 \mathrm{~cm}, 12 \mathrm{~cm}$ and $13.50 \mathrm{~cm}$. The mobility of the veil was good in 9 patients (75\%), more or fair in 2 patients (16.67\%), and bad in one patient. In addition, a patient had a deviation from the uvula.

Swallowing was normal for 10 patients (83.34\%). False routes were present in 
one case (the patient with poor mobility of the veil).

\subsection{Distribution of Patients According to the Phonatory Result}

Phonation was evaluated for 9 patients. Type I (no nasal) was noted in 7 patients (77.78\%), Type II (with intermittent nasalization) in 1 patient $(11.11 \%)$, and Type III B (acceptable phonation) in 1 patient (11.11\%).

\section{Discussion}

A retrospective study of descriptive type was conducted. It involved 13 patients with cleft palate who underwent surgical management according to the modified Furlow technique.

To our knowledge, this is the first study examining the Furlow technique in Guinea. Although the small sample size of patients evaluated cannot produce definitive conclusions, the study shows the technique remains a reliable surgical alternative for palatal cleft management.

In this study, the average age of patients was 6.9 years with a range of 7 months and 17 years. The $0-5$ age group was the most represented at $53.85 \%$. In the Democratic Republic of Congo, Sangwa CM et al. [11], in 2014, reported 62\% of patients were older than 5 years with an average age of 11.8 years. A study conducted in France by Doray B et al. [12], in 2012, showed that CP were diagnosed by antenatal ultrasound in $52 \%$ of cases. In the African context, the high average age of patients at intervention may be due to poor socio-economic conditions, lack of specialists, and paucity of other essential facilities equipped for the procedure. In addition, ultrasound scans for perinatal $\mathrm{CP}$ are not routinely performed.

The study found that females were the most affected (61.54\%) with a sex ratio of 0.62. This result corroborates to the study of Berail A et al. [13] in France in 2015. They study recorded $59,1 \%$ of patients as female. However, this is in contrast with Longombe AO et al. [14], in 2012, and Sangwa CM [11], in 2014 in Democratic Republic of Congo that reported a male predominance.

In this study, the modified Furlow technique was used to repair the palate in all patients. This technique was associated with Millard cheiloplasty in $38.47 \%$ of cases. Primary repair of the palate was performed in 11 patients $(84.61 \%)$. Immediate operative follow-up was done. No immediate postoperative complication of hemorrhagic type, infection, fistula, dehiscence, and velopalatine insufficiency was observed. Complete closure of the clefts and the epithelialization of the fat flaps in 4 weeks were noted in all patients. Levi B et al. [8] in the United States in 2009, used the same technique for 14 patients. They performed the primary repair in 10 patients and the 4 others were operated for fistulas. They observed complete epithelialization in 2 weeks without postoperative fistula. The epithelialization results from the fact that the Bichat ball's superficial adipose tissue, once placed and sutured at the margins of the cleft palate, is replaced by a squamous epithelium that extends on the neighboring tissues. These results con- 
firm the advantages associated with the use of Bichat fat flap evoked by Levi B et al. [8]. According to these authors, the Bichat ball is a tissue that is highly vascularized autonomously, preventing fistulas. Its removal leads to a low risk of morbidity of the donor site.

To evaluate late postoperative complications, patients were followed for a period of 4 years. During this period 12 patients were reevaluated, 11 or $91.67 \%$ did not present any complications and 1 case $(8.33 \%)$ of fistula was noted. In the United States in 2013, Jackson et al. [6] reported a fistula rate of 5.2\% after an average follow-up of 6.7 years. Edwin KW et al. [15] in China in 2014, compared this technique to the one of Von Langhenbeck reporting a fistula rate of $5.1 \%$ versus $11.6 \%$ for the Langhenbeck technique. In contrast, Abdel Aziz M et al. [4] found no case of fistula after an average follow-up of 12 months. Fistula complication is usually related to the tension of the sutures at the time of CP closure and the surgeon's experience. The size of the cleft and the development of the palatal musculature are also very important intrinsic factors to take into account for the occurrence of postoperative fistulas [16].

Over the last ten years, numerous studies [17] [18] [19] to evaluate palatal lengthening after palatoplasty using the Furlow technique have been conducted around the world. The measurement of the length of the palate was completed in the operating room at the time of the intervention and immediately postoperative. In this work, these measurements were performed to the patients 4 years after the intervention. An average elongation of $9.44 \mathrm{~cm}$ was obtained. Unlike other studies, the preoperative measurement was not performed. This would have made it possible to assess the average postoperative elongation of the veil. Dantonio et al. [20] have shown in their study that this technique significantly increases the length and thickness of the palate, leading to better phonatory results. We found 7 patients $(77.78 \%)$ with a phonatory result of type I (no nasality) according to the Borel-Maisonny [10] classification and 1 case (11.11\%) of type II (with intermittent nasality). One patient had a phonation of type III M with labored communication. However, type III B phonatory disorders (acceptable phonation) with nasotherapy was recorded in 1 patient. This is in contrast with Jackson O et al. [6] who reported $90.2 \%$ of patients had good phonation without nasonation, and good articulation in $96.8 \%$ of cases at an average age of 1.1 years after surgery. In Egypt, Abdel Aziz M [18] in 2013 found that $85.7 \%$ of patients had good phonation, and $14.3 \%$ a nasal voice with an average age of 4 months at the time of intervention. These phonatory disorders observed in our study can be explained by the high age of the patients at the time of the surgery. Thus, the delay related to the treatment may favor the occurrence of the articulatory problems and the phenomena of compensation hindering the normal development of the language. There is still controversy around the age at which palatoplasty should be performed. Some authors [18] [20] [21] recommend closing at an early age to get good phonation. According to Kalpan EN [22], the ideal time for CP repair is 3 to 6 months. When it is delayed beyond 2 years, the 
chance of getting a normal phonation is minimal.

The inability to reach some patients, the refusal of others to participate in the study and the lack of equipment used to assess swallowing, were the main limitations of this study.

\section{Conclusion}

The birth of a child with cleft palate initially leads to a social problem, then to a functional problem that affects the diet and the normal development of language. Adequate management requires multidisciplinary collaboration. Furlow's modified technique is an effective technique in the surgical repair of palatal clefts because it reduces the occurrence of immediate and long-term postoperative complications. However, the delay in repairing the palate remains a real obstacle to obtaining a normal phonation.

\section{Acknowledgements}

We sincerely thank the staff of Odontostomatology and Maxillofacial Surgery and ENT departments for record keeping and records that were used to conduct this study.

\section{Ethical Approval}

Authors obtained the approval of the ethics committee of the University for the conduct of this study.

\section{Conflicts of Interest}

Authors declare that there is no any conflict of interest.

\section{References}

[1] Benamor, M., Mbareck, Messaoud, I., Hariga, I., Bouzaiani, A., Ben Gamara, O., et al. (2010) Prise en charge des fentes Labiovelopalatines. Journal Tunisien d Otorhinolaryngologie, 24, 45-48.

[2] François-Fiquet, C., Dupouy, M., Daoud, S. and Poli-Merol, M.L. (2015) Fentes labio-palatines: Qualité de vie (VSP-A) patients et parents. À propos de 51 familles. Annales de Chirurgie Plastique Esthétique, 60, 192-200.

https://doi.org/10.1016/j.anplas.2014.08.008

[3] Nadjimi, N., Van Erum, R., Debot, E.M. and Bronkhorst, E.M. (2013) Two-Stage Palatoplasty Using a Modified Furlow Procedure. International Journal of Oral and Maxillofacial Surgery, 42, 555-558. https://doi.org/10.1016/j.ijom.2012.12.003

[4] Mossad, A.A., Nassar, A., Rashed, M., Naguib, N. and El-Tahan, A.R. (2015) Furlowpalatoplasty for Previously Repaired Cleft Palate with Velopharyngeal Insufficiency. International Journal of Pediatric Otorhinolaryngology, 79, 1748-1751. https://doi.org/10.1016/j.ijporl.2015.07.044

[5] Horswell, B.B. (2009) Primary Palatoplasty: Double-Opposing Z-Plasty Furlow Technique. Atlas of the Oral and Maxillofacial Surgery Clinics of North America, 17, 157165. https://doi.org/10.1016/j.cxom.2009.05.004

[6] Jackson, O., et al. (2013) The Children's Hospital of Philadelphia Modification of the 
Furlow Double Opposing Z-Palatoplasty: 30 Year Experience and Long Term Speech Outcomes. Plastic and Reconstructive Surgery, 132, 613-622. https://doi.org/10.1097/PRS.0b013e31829ad109

[7] Gupta, R., Kumar, S., Murarka, A.K. and Moward, A. (2011) Some Modifications of the Furlow Palatoplasty in Wide Clefts: A Preliminary Report. The Cleft PalateCraniofacial Journal, 48, 9-19. https://doi.org/10.1597/09-051

[8] Levi, B., Kasten, S.J. and Buchman, S.R. (2009) Utilization of the Buccal Fat Pad Flap for Congenital Cleft Palate Repair. Plastic and Reconstructive Surgery, 123, 10181021. https://doi.org/10.1097/PRS.0b013e318199f80f

[9] Singh, J., Prasad, K., Lalitha, R.M., Ranganath, K. and Bangalore, K. (2010) Buccal Pad of Fat and Its Applications in Oral and Maxillofacial Surgery: Are View of Published Literature (February) 2004 to (July) 2009. Oral Surgery, Oral Medicine, Oral Pathology, and Oral Radiology, 110, 698-705.

https://doi.org/10.1016/j.tripleo.2010.03.017

[10] Borel-Maisonny, S. (1975) Les troubles du langage, de la parole et de la voix chez l'enfant, Masson.

[11] Sangwa, C.M., Mukuku, O., Tschisuz, C., Panda, J.M., Kalinga, M., Kitembo, M.F. and Mutomb, J.F. (2014) Les Fentes labiopalatines dans la province de Katanga en RDC: Aspects épidémiologique, anatomoclinique et thérapeutique. Pan African Medical Journal, 17, 319. https://doi.org/10.11604/pamj.2014.17.319.4268

[12] Doray, B., BadilaTimbolschi, D., Fattori, D., Monga, B., Dott, B. and Favre, R. (2012) Epidémiologie des fentes faciales (1995-2006) en France (malformations congénitales) du registre Alsace. Archives of Pediatrics, 19, 1021-1029.

https://doi.org/10.1016/j.arcped.2012.07.002

[13] Bèrail, A., Lauwers, F., NoirritEsclassan, E., Woisard Bassols, V., Gardini, B. and Galinier, P. (2015) Epidémiologie des malformations associées aux fentes labiales et palatines à propos d'une étude rétrospective de 324 cas. Archives of Pediatrics, 22, 816-821. https://doi.org/10.1016/j.arcped.2015.05.005

[14] Longombe, A.O. and TshimbilaKabangu, J.M.V. (2012) Les fentes labiopalatines à l'Est de la République Démocratique du Congo. Aspects épidémiologiques. Annales de Chirurgie Plastique Esthétique, 57, 245-249.

https://doi.org/10.1016/j.anplas.2012.02.012

[15] Edwin, K.W., Kim, H.L., et al. (2014) From Von Langhenbeck to Furlow Palatoplasty: A 16 Years Review of Cleft Palate Repair. Surgical Practice, 18, 67-71. https://doi.org/10.1111/1744-1633.12054

[16] Li, C.-H., Shi, J.-Y., Zheng, Q., et al. (2014) The Children's Hospital of Philadelphia Modification of Furlow Double-Opposing Z-Palatoplasty: 30 Year Experience and Long-Term Speech Outcomes. Plastic and Reconstructive Surgery, 133, 429-431. https://doi.org/10.1097/PRS.0000000000000157

[17] Liu, M.M. and Jeehong, K.N. (2014) Teaching Furlow Palatoplasty: The Sticky Not Method. International Journal of Pediatric Otorhinolaryngology, 78, 1849-1851. https://doi.org/10.1016/j.ijporl.2014.08.006

[18] Abdel Aziz, M. (2013) Speech Outcome after Early Repair of Cleft Soft Palate Using Furlow Technique. International Journal of Pediatric Otorhinolaryngology, 77, 85-86. https://doi.org/10.1016/j.ijporl.2012.09.038

[19] Ashianti, A.K., Bobluli, B., Motamendi, M.H.K., Fatemi, M.J. and Mobaramnejad, N. (2011) Effectiveness of Buccal Fat in Closing Residual Mid Palatal and Posterior Palatal Fistulas in Patients Previously Treated for Clefts. Journal of Oral and Maxillofacial Surgery, 69, 416-419. https://doi.org/10.1016/j.joms.2011.02.010 
[20] D’Antonio, L.L., Eichenberg, B.J., Zimmerman, G.J., et al. (2000) Radiographic and Aerodynamic Measures of Velopharyngeal Anatomy and Function Following Furlow Z-Plasty. Plastic and Reconstructive Surgery, 106, 539-549. https://doi.org/10.1097/00006534-200009030-00002

[21] Barimo, J.P., Habal, M.B., Scheuerle, J. and Ritterman, S.I. (1987) Postnatal Palatoplasty, Implications for Normal Speech Articulation Preliminary Report. Scandinavian Journal of Plastic and Reconstructive Surgery and Hand Surgery, 21, 139-143. https://doi.org/10.3109/02844318709083593

[22] Kaplan, E.N. (1981) Cleft Palate Repair at Three Months? Annals of Plastic Surgery, 7, 179-190. https://doi.org/10.1097/00000637-198109000-00001 